\title{
Mortality and Major Morbidity of Very-Low-Birth-Weight Infants in Germany 2008-2012: A Report Based on Administrative Data
}

\author{
Elke Jeschke ${ }^{1}$, Alexandra Biermann ${ }^{1}$, Christian Günster ${ }^{1}$, Thomas Böhler ${ }^{2}$, \\ Günther Heller ${ }^{3}$, Helmut D. Hummler and Christoph Bührer ${ }^{* *}$ for the \\ Routine Data-Based Quality Improvement Panel'
}

${ }^{1}$ Wissenschaftliches Institut der Ortskrankenkassen, Berlin, Germany, ${ }^{2}$ Medizinischer Dienst der Krankenkassen BadenWürttemberg, Karlsruhe, Germany, ${ }^{3}$ Institut für Qualität und Transparenz im Gesundheitswesen, Berlin, Germany, ${ }^{4}$ Section Neonatology/Pediatric Intensive Care, Ulm University Children's Hospital, Ulm, Germany, ${ }^{5}$ Department of Neonatology, Charité University Medical Center, Berlin, Germany

Background: Expectant parents of very preterm infants, physicians, and policy makers require estimates for chances of survival and survival without morbidity. Such estimates should derive from a large, reliable, and contemporary data base of easily available items known at birth.

Objective: To determine short-term outcome and risk factors in very-low-birth-weight preterm infants based on administrative data.

Methods: Anonymized routine data sets transmitted from hospital administrations to statutory health insurance companies were used to assess survival and survival free of major morbidities in a large cohort of preterm infants in Germany.

Results: After exclusion of infants with lethal malformations, there were 13,147 infants with a birth weight below 1,500 g admitted to neonatal care 2008-2012, of whom 1,432 infants (10.9\%) died within 180 days. Estimated 180 days survival probabilities were 0.632 (95\% confidence interval 0.583-0.677) for infants with 250-499 g birth weight, 0.817 (0.799-0.834) for 500-749 g, 0.931 (0.920-0.940) for 750-999 g, 0.973 (0.967-0.979) for 1,000-1,249 g, and 0.985 (0.981-0.988) for 1,250-1,499 g. Estimated probabilities for survival without major morbidity (surgically treated intraventricular hemorrhage, necrotizing enterocolitis, intestinal perforation, or retinopathy) were 0.433 (0.384-0.481) for 250-499 g, 0.622 (0.600-0.643) for 500-749 g, 0.836 (0.821-0.849) for 750-999 g, 0.938 (0.928-0.946) for 1,000-1,249 g, and 0.969 (0.964-0.974) for 1,250-1,499 g, respectively. Prediction of survival and survival without major morbidities was moderately improved by adding sex, small for gestational age, and severe or moderate congenital malformation, increasing receiver operating characteristic areas under the curve from $0.839(0.827-0.850)$ to $0.862(0.852-0.874)$ (survival) and from $0.827(0.822-0.842)$ to 0.852 (0.846-0.863) (survival without major morbidities), respectively.

Conclusion: The present analysis encourages attempts to use administrative data to investigate the association between risk factors and outcome in preterm infants.

Keywords: preterm infant, mortality, morbidity, risk factor, predictive power 


\section{INTRODUCTION}

In threatened preterm delivery at the threshold of viability, estimating the chances for survival and survival without major morbidities of very preterm infants becomes pivotal when parents and physicians are faced with decisions to begin or withhold treatment. Furthermore, it is also important when designing interventional trials or for making adjustments in quality improvement efforts that compare hospital performance. Outcome of preterm infants largely depends on birth weight and gestational age, and these variables remain the most commonly used denominators in population-based reports (1-9). National recommendations to initiate or withhold treatment at the threshold of viability are mostly based on gestational age (10), while the European Resuscitation Council discourages resuscitative efforts in infants below 23 weeks gestational age or those with a birth weight below $400 \mathrm{~g}$ (11). The likelihood of a favorable outcome may be predicted more accurately when further factors present at birth are taken into account (12). The U.S. National Institute of Child Health and Human Development (NICHD) Neonatal Research Network, analyzing data of 4,446 preterm infant with a birth weight of 401-1,000 g admitted 1998-2003 to 19 U.S. hospitals, has demonstrated that prediction of survival and survival without major neurodevelopmental impairment can be better estimated by consideration of five a priori selected factors (birth weight, gestational age, sex, exposure to antenatal corticosteroids, multiple gestation) than with use of gestational age alone (13). Two subsequent population-based studies in Victoria, Australia (2005, 114 infants) (14) and California, USA (2005-2008, 4,527 infants) (15) confirmed that using the five variables gave superior power to predict mortality than using gestational age only, although prediction of mortality for outborns was poor. The Canadian Neonatal Network has provided graphical representations of the probabilities of survival and survival without major morbidities calculated from gestational age, birth weight, and sex of 17,148 preterm infants admitted 2003-2008 to all major level III neonatal intensive care units in Canada, excluding only those with lethal congenital anomalies, primary palliation, missing values, or extreme outliers (16). The predictive power of the model was only marginally improved upon addition of the further variables, such as antenatal steroids, multiple gestation, mode of delivery, and maternal smoking, while it increased with inclusion of variables reflecting the clinical course during the first $24 \mathrm{~h}$ of life (17).

Rates of survival and survival without major morbidities vary considerably between countries, and they tend to improve over time $(4,7,8,18-20)$. Thus, there is a need to analyze actual regional or national data to meet the demand for contemporaneous outcome estimates. Here, we report rates of 180 days survival and survival free of major morbidities in preterm infants below 1,500 g birth weight in Germany 2008-2012 based on birth

\footnotetext{
Abbreviations: ICD, international classification of diseases; ICPM, international classification of procedures in medicine; IVH, intraventricular hemorrhage; NEC, necrotizing enterocolitis; NICHD, National Institute of Child Health and Human Development; OR, odds ratio; ROC, receiver operator characteristics; ROP, retinopathy of prematurity; VEGF, vascular endothelial growth factor.
}

weight and assessed the impact of risk factors on outcome of these infants.

\section{MATERIALS AND METHODS}

In Germany, family health insurance is mandatory for all employees with an annual income below 53,550 €, including recipients of unemployment benefits or welfare. In total, more than $90 \%$ of the population are covered by this statutory health insurance. While individuals can choose freely among 132 statutory health insurance providers, regardless of age, morbidities, income, or type of employment, there are 11 large regional health care funds covering about $33 \%$ of the persons insured. These large regional health care funds jointly run a scientific institute entrusted with collecting routine patient data sets sent from the hospital administrations to these 11 statutory health insurance companies to obtain reimbursement. The data sets that also contain the date the health insurance ends because the patient has died or changed the company are analyzed in an anonymized fashion to support quality improvement initiatives and provide health policy makers with decision aids.

We present an analysis of the data sets of live-born preterm infants born between January 1, 2008 and December 31, 2012 with a birth weight of 250-1,499 g who were admitted to hospital care within the first $24 \mathrm{~h}$ life and covered by one of the 11 regional health care funds. The routine data sets transmitted from the hospital administrations to the insurance companies to receive reimbursements include diagnoses (ICD-10), major procedures (German version of ICPM), sex, and weight on admission (for infants below 1 year of age).

We analyzed only data of infants admitted to neonatal care, any stillborn infants and intrapartum deaths were excluded, as were infants with lethal malformations. Malformations and congenital diseases were considered lethal, severe, or moderate according to their 180 days mortality rate in very-low-birth-weight infants calculated from the regional health care fund data base $(>66 \%$, lethal: thanatophoric dysplasia, anencephaly, bilateral renal agenesis, Potter sequence, autosomal-dominant polycystic kidney disease, bladder exstrophy, trisomy 13 or 18, tri- or polyploidy, hypoplastic left heart syndrome, double outlet right ventricle, aortic atresia, non-immune fetal hydrops; 33-66\%, severe: spina bifida, urea cycle defects, congenital diaphragmatic hernia, common arterial trunk, discordant ventriculoarterial connection, double inlet ventricle, total anomalous pulmonary venous connection; 16.5-32.9\%, moderate: esophageal atresia, omphalocele, non-autosomal-dominant polycystic kidney disease, tetralogy of Fallot, aortic coarctation, other congenital heart diseases). A priori selected predictor variables were birth weight (entered as categorical variable per $100 \mathrm{~g}$ increments), severe and moderate malformations, small for gestational age, sex, and multiple gestation $(8,12,13,21)$. Endpoints were mortality up to 180 days of life (during the first hospitalization, any subsequent hospitalizations, or at home) and any surgical interventions performed during the first 180 days of life for high-grade intraventricular hemorrhage (IVH), necrotizing enterocolitis (NEC)/spontaneous intestinal perforation, or retinopathy of prematurity (ROP). Any brain surgery in infants with IVH, such as shunt placement or endoscopic 
drainage, was considered surgical intervention, as was drainage or laparotomy in infants with NEC or spontaneous intestinal perforation. For ROP, cryotherapy, laser treatment, and intravitreal injections of any of the anti-VEGF drugs bevacizumab, ranibizumab, aflibercept, or pegaptanib were considered surgical interventions.

Statistical analyses were carried out using STATA (Version 11.2, Stata Corp, College Station, TX, USA). Kaplan-Meier analysis was used to describe survival up to 180 days and survival without major neonatal morbidity, with strata being compared by the log-rank test. The impact of predictor variables was assessed with adjusted odds ratios (OR) in multiple logistic regression analyses. To describe the power to predict survival and survival without major neonatal morbidity, receiver operating characteristics (ROC) curves were generated, and the areas under the curve with $95 \%$ confidence intervals were calculated.

The study received institutional review board approval (Ethikkommission der Charité Universitätsmedizin Berlin, \# EA2/136/14). No consent was required as this is a retrospective analysis of anonymized data collected according to federal law.

\section{RESULTS}

A total of 13,303 infants covered by the regional statutory health insurance companies were born between January 1, 2008 and December 31, 2012 with a birth weight between 250 and 1,499 g. Of these, 156 were excluded (stillborn, $n=17$; lethal malformations: $n=128$, twins with identical numbers: $n=17$ ). The characteristics of the 13,147 patients included are given in Table 1 . There were 143 cases $(1.09 \%)$ with incomplete data sets due to a change of the insurance company within 180 days after birth. There were a higher percentage of girls ( 51.2 vs. $48.7 \%, p=0.0216)$ and small-for-gestational-age babies ( 21.4 vs. $18.4 \%, p=0.0004)$ in infants with a birth weight of $250-749 \mathrm{~g}$, as compared to infants of 750-1,499 g, while the opposite was observed for multiples (11.4 vs. $20.7 \%, p=0.0001$ ).

Mortality within 180 days of life was $10.9 \%(1,432 / 13,147)$ in the total group, and $22 \%(1,229 / 5,584)$ in infants below $1,000 \mathrm{~g}$ birth weight (Table 2). Estimated probabilities (95\% confidence intervals) of 180 days survival were 0.632 (0.5831-0.677) for infants with a birth weight of 250-499 g, 0.817 (0.799-0.834) for 500-749 g, $0.931(0.920-0.940)$ for $750-999 \mathrm{~g}, 0.973$ (0.967-0.979) for 1,000-1,249 g, and $0.985(0.981-0.988)$ for 1,250-1,499 g, respectively (Figure 1). On average, $202(14.1 \%)$ of deaths occurred between 30 and 180 days of life (Table 2), of which 35 (2.4\%) were observed after discharge.

Major neonatal morbidities with surgical interventions occurred in 1022/13,147 (7.8\%) infants. Estimated probabilities of 180 days survival without major morbidity were 0.433 (0.384-0.481) for 250-499 g, $0.622(0.600-0.643)$ for $500-749 \mathrm{~g}$, $0.836(0.821-0.849)$ for $750-999 \mathrm{~g}, 0.938(0.928-0.946)$ for $1,000-1,249 \mathrm{~g}$, and $0.969(0.964-0.974)$ for $1,250-1,499 \mathrm{~g}$, respectively (Figure 2). Overall, there were 888 (6.8\%), $123(0.9 \%)$, and $11(0.08 \%)$ infants suffering from one, two, or three morbidities, respectively (Figure 3), and $782(6.7 \%)$, $116(1.0 \%)$, and $10(0.09 \%)$ in survivors (Figure 4). Among the 474 infants who had undergone surgery for NEC/intestinal perforation, there were 97 deaths $(20.5 \%)$, as compared to $15 / 296$ (5.1\%) after surgery for IVH, and 11/397 (2.7\%) after intervention for ROP.

Multiple logistic regression analysis was used to estimate the impact of the a priori selected predictor variables birth weight (per each 100-g increment, with the group of infants with a birth weight of 1,400-1,499 g serving as reference), sex, small for gestational age, multiple gestation, moderate, and severe congenital malformations, on survival and survival without major morbidity (Table 3). Except for multiple gestation, all of the a priori selected variables retained a statistically significant association with both death and death or survival with major morbidity upon multiple regression analysis.

The areas under the ROC to predict survival and survival without major morbidity were $0.862(0.852-0.874)$ and 0.852 (0.846-0.863) taking the $a$ priori selected variables into account, as compared to $0.839(0.827-0.850)$, and $0.827(0.822-0.842)$ when only birth weight was used (Figure 5). ROC areas were smaller when looking only at infants below $1,000 \mathrm{~g}$ birth weight [full model: $0.800(0.785-0.815)$ for survival, 0.785 (0.772-0.797) for survival without major morbidity; birth weight only: 0.771 (0.755-0.786) for survival, $0.746(0.732-0.760)$ for survival without major morbidity].

\section{DISCUSSION}

This analysis reports an overall 180 days survival rate of preterm infants with a birth weight $<1,500 \mathrm{~g}$ admitted to neonatal intensive care units in Germany 2008-2012 of $89.1 \%$, with $14.1 \%$ of deaths occurring between 30 and 180 days of life. Surgically treated major morbidities were observed in $7.7 \%$ of all verylow-birth-weight infants, and $7.8 \%$ of survivors, respectively.

TABLE 1 | Patients' characteristics stratified by birth weight.

\begin{tabular}{|c|c|c|c|c|c|c|}
\hline & $\begin{array}{l}\text { Total } \\
N(\%)\end{array}$ & $\begin{array}{c}250-499 \mathrm{~g} \\
N(\%)\end{array}$ & $\begin{array}{c}500-749 \mathrm{~g} \\
N(\%)\end{array}$ & $\begin{array}{c}750-999 \mathrm{~g} \\
N(\%)\end{array}$ & $\begin{array}{c}1000-1249 \mathrm{~g} \\
N(\%)\end{array}$ & $\begin{array}{c}1,250-1,499 \mathrm{~g} \\
N(\%)\end{array}$ \\
\hline Number & $13,147(100)$ & $673(100)$ & $2,147(100)$ & $2,764(100)$ & $3,061(100)$ & $4,502(100)$ \\
\hline Girls & $6,473(49.2)$ & $353(52.5)$ & 1,090 (50.8) & $1,351(48.9)$ & 1,478 (48.3) & 2,201 (48.9) \\
\hline Small for gestational age & $2,502(19.0)$ & $216(32.1)$ & $387(18.0)$ & $434(15.7)$ & $566(18.5)$ & $899(20.0)$ \\
\hline Multiple gestation & $2,456(18.7)$ & $94(14.0)$ & $328(15.8)$ & $498(18.0)$ & $556(18.2)$ & $980(21.8)$ \\
\hline Severe malformations & $53(0.4)$ & $3(0.5)$ & $7(0.3)$ & $6(0.2)$ & $14(0.5)$ & $23(0.5)$ \\
\hline Moderate malformations & $128(1.0)$ & $13(1.9)$ & $20(0.9)$ & $26(0.9)$ & $23(0.8)$ & $46(1.0)$ \\
\hline
\end{tabular}


TABLE 2 | Mortality and major morbidity stratified by birth weight.

\begin{tabular}{|c|c|c|c|c|c|c|}
\hline & $\begin{array}{l}\text { Total } \\
N(\%)\end{array}$ & $\begin{array}{c}250-499 \mathrm{~g} \\
N(\%)\end{array}$ & $\begin{array}{c}500-749 \mathrm{~g} \\
N(\%)\end{array}$ & $\begin{array}{c}750-999 \mathrm{~g} \\
N(\%)\end{array}$ & $\begin{array}{c}1,000-1,249 \mathrm{~g} \\
N(\%)\end{array}$ & $\begin{array}{c}1,250-1,499 \mathrm{~g} \\
N(\%)\end{array}$ \\
\hline Numbers (percentage) & $13,147(100)$ & $673(100)$ & $2,147(100)$ & $2,764(100)$ & $3,061(100)$ & $4,502(100)$ \\
\hline \multicolumn{7}{|l|}{ Mortality } \\
\hline - Within 30 days of life & $1,230(9.4)$ & $394(58.4)$ & $477(22.2)$ & $195(7.1)$ & $88(2.9)$ & $76(1.7)$ \\
\hline - Within 180 days of life & $1,432(10.9)$ & $417(62.0)$ & $565(26.3)$ & $247(8.9)$ & $110(3.6)$ & $93(2.1)$ \\
\hline \multicolumn{7}{|l|}{ Major neonatal morbidity } \\
\hline $\begin{array}{l}\text { - Intraventricular hemorrhage, surgical treatment within } \\
\text { first } 180 \text { days of life }\end{array}$ & $296(2.3)$ & $13(1.9)$ & $78(3.6)$ & $106(3.8)$ & $59(1.9)$ & $40(0.9)$ \\
\hline $\begin{array}{l}\text { - Necrotizing enterocolitis or intestinal perforation, surgical } \\
\text { treatment within first } 180 \text { days of life }\end{array}$ & $474(3.6)$ & $43(6.4)$ & $199(9.3)$ & $142(5.1)$ & $57(1.9)$ & $33(0.7)$ \\
\hline $\begin{array}{l}\text { - Retinopathy of prematurity, local treatment (cryo, laser, } \\
\text { anti-VEGF injection) within first } 180 \text { days of life }\end{array}$ & $397(3.0)$ & $60(8.9)$ & $227(10.6)$ & $88(3.2)$ & $18(0.6)$ & $4(0.1)$ \\
\hline \multicolumn{7}{|l|}{ Alive at 180 days } \\
\hline - Without major morbidity & $10,807(82.2)$ & 174 (25.9) & $1,200(55.9)$ & $2,257(81.7)$ & $2,841(92.8)$ & 4,335 (96.3) \\
\hline - With one major morbidity & $782(5.9)$ & $64(9.5)$ & $322(15.0)$ & $222(8.0)$ & $100(3.3)$ & $74(1.6)$ \\
\hline - With more than one major morbidity & $126(1.0)$ & $18(2.7)$ & $60(2.8)$ & $38(1.4)$ & $10(0.3)$ & $0(0.0)$ \\
\hline - Total & $11715(89.1)$ & $256(38.0)$ & $1582(73.7)$ & $2517(91.1)$ & $2957(96.6)$ & $4409(97.9)$ \\
\hline
\end{tabular}

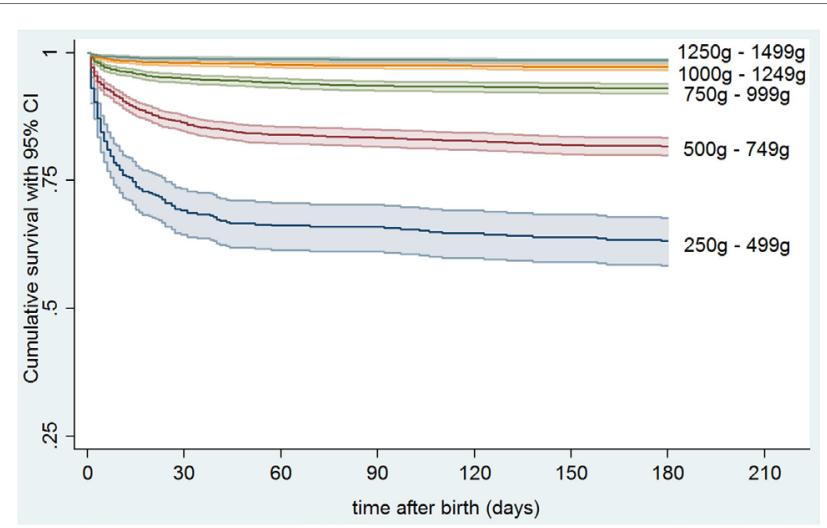

FIGURE 1 | Kaplan-Meier estimates for survival up to 180 days of life in preterm infants stratified by birth weight

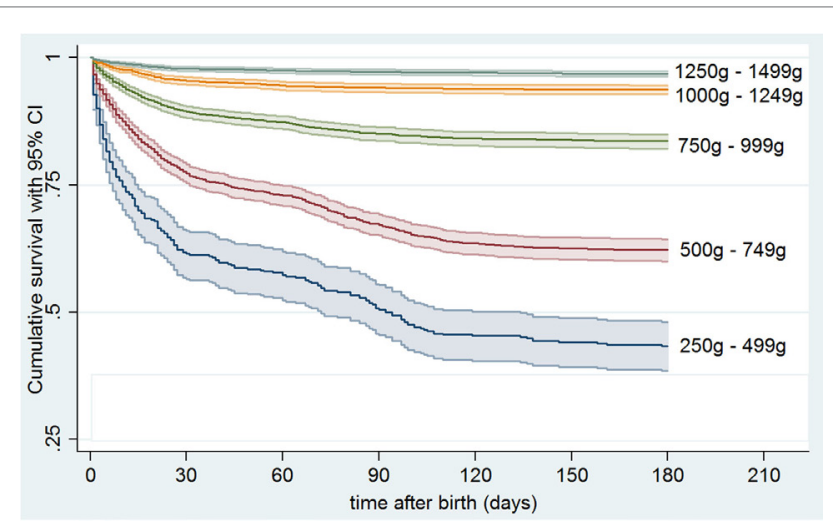

FIGURE 2 | Kaplan-Meier estimates for survival up to 180 days of life without major morbidity (surgically treated intraventricular hemorrhage, necrotizing enterocolitis/intestinal perforation, or retinopathy of prematurity) in preterm infants stratified by birth weight.

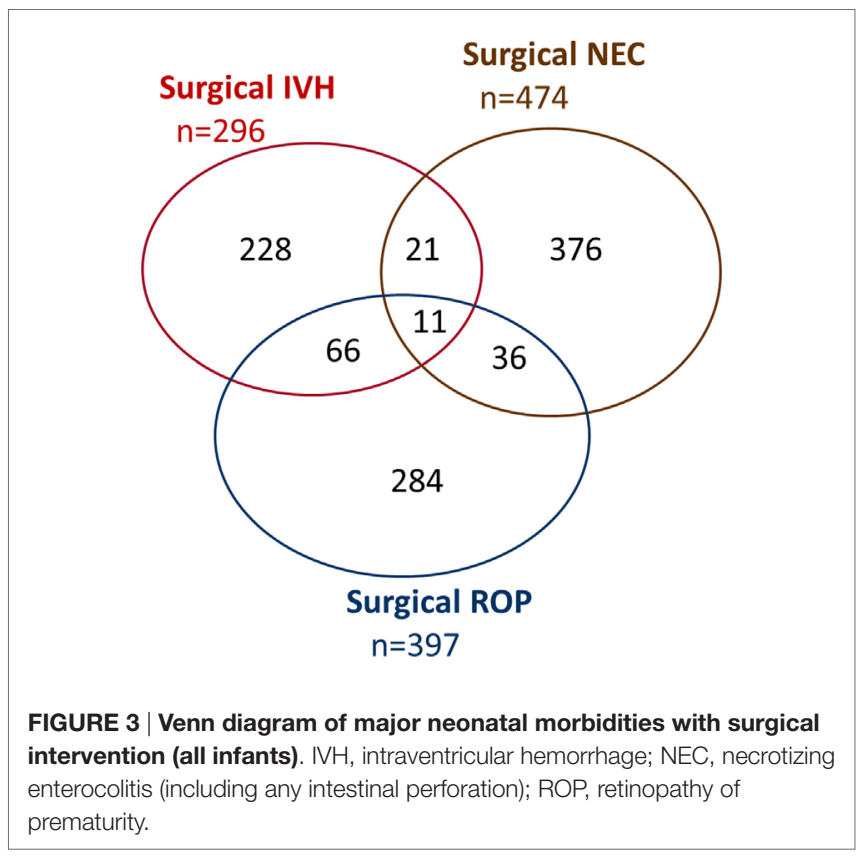

Rates of survival strongly declined alongside decreasing birth weight, from $97.9 \%$ in $1,250-1,499 \mathrm{~g}$ birth weight infants to $38 \%$ in infants below $500 \mathrm{~g}$ birth weight, while the rates of surgically treated major morbidities in survivors increased from 1.7 to $32 \%$.

We compared our data with published data of a cohort of 2,207 infants below 1,500 $\mathrm{g}$ birth weight without lethal malformations treated in 2010 in a network of 46 tertiary care neonatal units in Germany (22). The published survival rate prior to discharge in this network-based cohort (90.6\%) was virtually identical to the 30 days survival rate observed in the 2008-2012 data set. We also compared our data with those of cohorts from other countries. For infants below $1,000 \mathrm{~g}$ birth weight admitted to neonatal care, reported survival at 2 years was $70.8 \%(613 / 866)$ 
in a Swiss population-based cohort 2000-2008 (7), as compared with $78 \%(4,355 / 5,584) 180$ days survival in the German 2008-2012 cohort. Unfortunately, most published reports do not provide survival rates by birth weight, and survival figures are given at differing time points - prior to discharge $(4,19)$, at 1 year (18), or at 2 years of life (9). Some crude comparisons, however, are made possible by the similarity of average birth weights $(730-750 \mathrm{~g})$ in cohorts of preterm infants $<27$ weeks gestation (730-750 g) in Sweden (18), England (4), France (19), and the United States (9), and infants $<1,000 \mathrm{~g}$ birth weight who

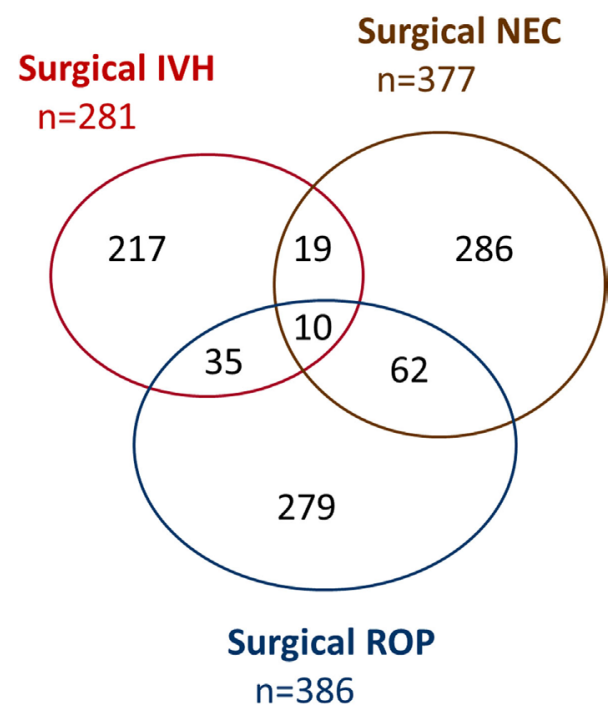

FIGURE 4 | Venn diagram of major neonatal morbidities with surgical intervention (survivors only). IVH, intraventricular hemorrhage; NEC, necrotizing enterocolitis (including any intestinal perforation); ROP, retinopathy of prematurity. are subject of this study. The published 1-year or 2-year survival rates of the infants admitted to neonatal intensive care were $78.1 \%(497 / 636)$ in the Swedish EXPRESS cohort (2004-2007) and $65.0 \%(2,630 / 4,046)$ in the American NICHD network (2006-2011), respectively, while survival to discharge was $61.7 \%$ $(1,041 / 1,686)$ in the English EPICure2 (2006) cohort and $69.0 \%$ (552/800) in the French EPIPAGE2 (2011) cohort. Of note, these outcome data are influenced by physicians' and parents' choices on which infants to admit to neonatal care. We assume that the lower percentages of boys and multiples we observed in preterm infants with 250-749 g birth weight admitted to neonatal care, as compared to infants with 750-1,499 g birth weight, are most likely a reflection of such choices.

Outcome was strongly related to birth weight, with risks for mortality or major morbidity on average doubling for each $20-25 \%$ decrease in birth weight. The impact of birth weight and the other a priori selected variables on death and death and major morbidity combined was remarkably similar. Multiple gestation was not linked to poor outcome, an observation made for recent cohorts also in Australia and New Zealand (23). Small for gestational age was associated with reduced ORs for poor outcome as the investigation used birth weight as primary variable, the opposite would have been observed with gestational age as primary variable. While sex, small for gestational age, and malformations were independently associated with outcome, estimating chances for survival and survival without surgical morbidities based on birth weight alone was only slightly improved by the addition of these further variables. This is in line with previous observations, showing that birth weight alone was only slightly inferior than the clinical risk index for babies calculated from birth weight, gestational age, congenital malformations, base excess, and oxygen requirements during the first $12 \mathrm{~h}$ of life in predicting death or neurodevelopmental impairment at 1 year of age (24). The predictive power, as measured by the area under the ROC curve, was similar to that of similar published algorithms taking

TABLE 3 | Multivariate predictor variables for death or death/survival with major morbidity.

\begin{tabular}{|c|c|c|c|c|}
\hline Variable & OR death & $5-95 \% \mathrm{Cl}$ & OR death or survival with major morbidity & $5-95 \% \mathrm{Cl}$ \\
\hline \multicolumn{5}{|l|}{ Birth weight (g) } \\
\hline$<300$ & 2026.27 & $265.06-15,489.06$ & 578.61 & $131.77-2540.60$ \\
\hline $300-399$ & 269.96 & $166.15-438.61$ & 288.90 & 173.14-482.06 \\
\hline $400-499$ & 104.05 & $73.11-148.09$ & 105.93 & $77.58-144.65$ \\
\hline $500-599$ & 42.03 & $30.11-58.66$ & 47.25 & $35.85-62.28$ \\
\hline $600-699$ & 20.15 & $14.51-27.97$ & 26.63 & $20.53-34.54$ \\
\hline $700-799$ & 10.76 & $7.68-15.08$ & 12.15 & $9.34-15.79$ \\
\hline 800-899 & 5.62 & $3.93-8.06$ & 6.95 & $5.30-9.11$ \\
\hline 900-999 & 4.02 & $2.82-5.73$ & 4.99 & $3.83-6.50$ \\
\hline $1,000-1,099$ & 3.37 & $2.20-5.17$ & 3.19 & $2.29-4.46$ \\
\hline $1,100-1,199$ & 1.92 & $1.26-2.93$ & 2.44 & $1.80-3.31$ \\
\hline $1,200-1,299$ & 1.39 & $0.90-2.15$ & 1.24 & $0.88-1.74$ \\
\hline $1,300-1,399$ & 1.35 & $0.86-2.11$ & 1.08 & $0.75-1.56$ \\
\hline $1,400-1,499$ & 1 & (Reference) & 1 & (Reference) \\
\hline Male & 1.59 & $1.40-1.82$ & 1.65 & $1.48-1.85$ \\
\hline Small for gestational age & 0.24 & $0.19-0.29$ & 0.23 & $0.19-0.28$ \\
\hline Multiple & 1.07 & $0.90-1.27$ & 1.08 & $0.94-1.25$ \\
\hline Moderate malformation & 1.68 & $1.11-2.55$ & 1.55 & $1.05-2.29$ \\
\hline Severe malformation & 17.34 & $9.52-31.58$ & 11.59 & $6.29-21.37$ \\
\hline
\end{tabular}




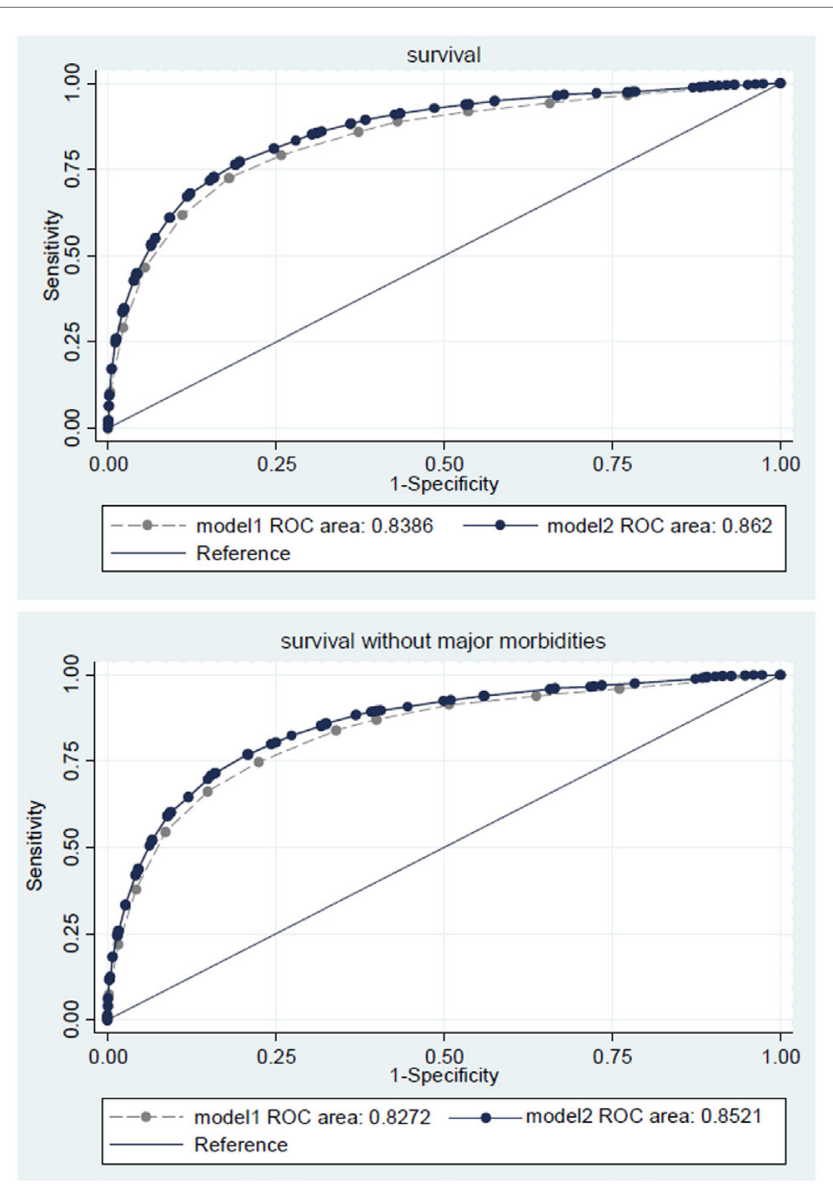

FIGURE 5 | Receiver operating characteristic (ROC) curve for survival (upper panel) or survival without major morbidities (lower panel) based on birth weight (model 1, dashed lines) or birth weight, small for gestational age, sex, multiple gestation, severe or moderate malformations (model 2, solid lines).

only variables into account that are known at birth $(13,16)$. Unfortunately, the lack of certain items in the data set available prevented any direct head-to-head comparison.

This study has several strengths and weaknesses. It is based on a large, contemporary cohort, with limited selection bias or loss to follow-up. Well-to-do individuals, however, are underrepresented in the cohort of the study, as self-employed persons and employees with an annual income above 53,550€ may choose private health insurance instead of statutory health insurance (about $10 \%$ of the population). This drawback is to be balanced against the risk of recruitment bias in prospective clinical trials, especially those that require antenatal parental consent (25), the risk of referral bias for data from networks of highly specialized groups of neonatal intensive care units, and bias introduced into observational studies by uneven loss to follow-up, with an excess of children from disadvantaged families who are not being evaluated face to face (26).

Our investigation was based on data from patients rather than cases, whereas events occurring after discharge or transfer to another hospital are being missed in unit-based network and quality improvement data sets. In contrast to other studies, the 180 days window allowed to take events after discharge or transfer to another hospital into account, unless there was a change in the company providing health care insurance. Late deaths are an important issue, especially in very small infants, with $13.3 \%$ of deaths occurring after 30 days of life in infants below $1,000 \mathrm{~g}$ birth weight. For comparison, 17.3 and $19.8 \%$ of all deaths occurred beyond 28 days of life in the American NICHD (8) and English EPICure2 cohorts (4), respectively.

As a major weakness, some variables of great interest to clinicians are missing, particularly gestational age at birth, antenatal steroids, mode of delivery, and inborn/outborn status. A merger of the anonymized infant administrative data sets, as used in this study, with maternal records is being hampered by current rules governing privacy protection. The variable "small for gestational age" partly made up for the missing variable "gestational age at birth," also avoiding the multicollinearity problem when birth weight and gestational age are entered simultaneously as continuous measures. The variable "antenatal steroids" has lost statistical impact as a result of the high rates of antenatal steroids and exogenous surfactant replacement therapy (27). As data verification or central review is not possible with anonymized data sets, we chose simple endpoints each representing an irreversible event marked with a calendar date (mortality, surgery for neonatal diseases) to reduce the risk of reporting bias. This also allowed for Kaplan-Meier analyses not possible with time varying variables that wax and wane during the clinical course, such as ROP or bronchopulmonary dysplasia.

High-grade IVH, high-grade ROP, and NEC requiring surgery have been shown to be strong predictors of long-term neurodevelopmental impairment $(7,28-35)$. The high interrater variability of disease severity for IVH, ROP, or NEC argues against their use as outcome measures, unless the severity is validated by a procedure. IVH, ROP, and NEC are diseases striking preterm infants with various intensities, and the presence of surgical interventions to treat these diseases was used to delineate severe from mild stages. This assumption may not be true in all cases, and counting only morbidity linked with a surgical intervention likely results in overestimation of survival without severe morbidity. However, as surgical procedures increase reimbursements paid to hospitals, the use of interventions as an outcome variable entails little risk of underreporting, in contrast to the mere diagnoses IVH, ROP, and NEC that are liable to down-coding. Abnormal cranial ultrasound findings may give misleading results, considering the high interobserver variability in assessment of cranial ultrasound findings $(36,37)$ and the poor correlation between high-grade IVH, as depicted by early cranial ultrasound, and neurodevelopmental impairment (37, 38). The association between NEC and poor neurodevelopmental outcome appears to be confined to infants with NEC-related abdominal surgery (29).

Data entered into any type of registry are liable to inadvertent mistakes, biased coding, or even wilful deceit. When estimating the risk of false entries, there are several questions to be addressed: (1) How reliable is the information given to the person who enters the data? (2) How likely are errors based on negligence? (3) Are there incentives for up-coding, 
down-coding, or omission of data? For these reasons, we chose to not include bronchopulmonary dysplasia as an outcome variable in this analysis, as it lacks an unambiguous marker to disassociate mild from severe forms unless strict definitions are being employed. Some degree of disordered lung development is common in very preterm infants, and it largely depends on the exact criteria used whether or not infants are classified as having bronchopulmonary dysplasia (39). For mortality, which is at center stage of this analysis, administrative data of insurance companies are probably better than data from anywhere else, as the death of a patient also implies the end of the insurance contract. By contrast, an analysis of the mandatory German neonatal registries (used to compare the performance of individual units) showed that more than $30 \%$ of extremely preterm infants born alive (by official birth registry) were not included in these registries (40).

Administrative data have been used successfully for as diverse purposes as to estimate live delivery rates after tubal sterilization reversal (41), to compare the risk of preterm birth among women living with and without HIV infection (42), to calculate the risk of hospital readmission among infants with neonatal abstinence

\section{REFERENCES}

1. Larroque B, Bréart G, Kaminski M, Dehan M, André M, Burguet A, et al. Survival of very preterm infants: epipage, a population based cohort study. Arch Dis Child Fetal Neonatal Ed (2004) 89(2):F139-44. doi:10.1136/ adc.2002.020396

2. Vanhaesebrouck P, Allegaert K, Bottu J, Debauche C, Devlieger H, Docx M, et al. The EPIBEL study: outcomes to discharge from hospital for extremely preterm infants in Belgium. Pediatrics (2004) 114(3):663-75. doi:10.1542/ peds.2003-0903-L

3. Leversen KT, Sommerfelt K, Rønnestad A, Kaaresen PI, Farstad T, Skranes $\mathrm{J}$, et al. Predicting neurosensory disabilities at two years of age in a national cohort of extremely premature infants. Early Hum Dev (2010) 86(9):581-6. doi:10.1016/j.earlhumdev.2010.07.009

4. Costeloe KL, Hennessy EM, Haider S, Stacey F, Marlow N, Draper ES. Short term outcomes after extreme preterm birth in England: comparison of two birth cohorts in 1995 and 2006 (the EPICure studies). BMJ (2012) 345:e7976. doi:10.1136/bmj.e7976

5. de Waal CG, Weisglas-Kuperus N, van Goudoever JB, Walther FJ, NeoNed Study Group, LNF Study Group. Mortality, neonatal morbidity and two year follow-up of extremely preterm infants born in The Netherlands in 2007. PLoS One (2012) 7(7):e41302. doi:10.1371/ journal.pone.0041302

6. Serenius F, Källén K, Blennow M, Ewald U, Fellman V, Holmsträm G, et al. Neurodevelopmental outcome in extremely preterm infants at 2.5 years after active perinatal care in Sweden. JAMA (2013) 309(17):1810-20. doi:10.1001/ jama.2013.3786

7. Schlapbach LJ, Adams M, Proietti E, Aebischer M, Grunt S, Borradori-Tolsa $\mathrm{C}$, et al. Outcome at two years of age in a Swiss national cohort of extremely preterm infants born between 2000 and 2008. BMC Pediatr (2013) 12:198. doi:10.1186/1471-2431-12-198

8. Patel RM, Kandefer S, Walsh MC, Bell EF, Carlo WA, Laptook AR, et al. Causes and timing of death in extremely premature infants from 2000 through 2011. N Engl J Med (2015) 372(4):331-40. doi:10.1056/NEJMoa1403489

9. Rysavy MA, Li L, Bell EF, Das A, Hintz SR, Stoll BJ, et al. Between-hospital variation in treatment and outcomes in extremely preterm infants. $N$ Engl J Med (2015) 372(19):1801-11. doi:10.1056/NEJMoa1410689

10. Pignotti MS, Donzelli G. Perinatal care at the threshold of viability: an international comparison of practical guidelines for the treatment of syndrome (43), or to examine patterns of pediatric emergency department visits $(44,45)$. The present analysis encourages attempts to use administrative data also to investigate the association between risk factors and outcome in preterm infants. When it comes to deciding which data to include in such administrative data sets, clinicians should be consulted to facilitate such investigations.

\section{AUTHOR CONTRIBUTIONS}

$\mathrm{EJ}, \mathrm{AB}, \mathrm{CG}, \mathrm{TB}, \mathrm{GH}, \mathrm{HH}$, and $\mathrm{CB}$ all contributed to the conception and design of this analysis. $\mathrm{EJ}, \mathrm{AB}$, and $\mathrm{CG}$ provided the statistical analysis, EJ and $\mathrm{CB}$ drafted the first manuscript that was revised by $\mathrm{AB}, \mathrm{CG}, \mathrm{TB}, \mathrm{GH}$, and $\mathrm{HH}$ and finally approved by all authors.

\section{ACKNOWLEDGMENTS}

We would like to thank the further members of the panel, Stefanie Konheiser, Klaus Vetter, Dieter Grab, and Jürgen Malzahn for their valuable contribution to this project. extremely preterm births. Pediatrics (2008) 121(1):e193-8. doi:10.1542/ peds.2007-0513

11. Wyllie J, Bruinenberg J, Roehr CC, Rudiger M, Trevisanuto D, Urlesberger B. European Resuscitation Council Guidelines for Resuscitation 2015: section 7. Resuscitation and support of transition of babies at birth. Resuscitation (2015) 95:249-63. doi:10.1016/j.resuscitation.2015.07.029

12. Medlock S, Ravelli AC, Tamminga P, Mol BW, Abu-Hanna A. Prediction of mortality in very premature infants: a systematic review of prediction models. PLoS One (2011) 6(9):e23441. doi:10.1371/journal.pone.0023441

13. Tyson JE, Parikh NA, Langer J, Green C, Higgins RD. Intensive care for extreme prematurity-moving beyond gestational age. N Engl J Med (2008) 358(16):1672-81. doi:10.1056/NEJMoa073059

14. Boland RA, Davis PG, Dawson JA, Doyle LW, Victorian Infant Collaborative Study Group. Predicting death or major neurodevelopmental disability in extremely preterm infants born in Australia. Arch Dis Child Fetal Neonatal Ed (2013) 98(3):F201-4. doi:10.1136/archdischild-2012-301628

15. Lee HC, Green C, Hintz SR, Tyson JE, Parikh NA, Langer J, et al. Prediction of death for extremely premature infants in a population-based cohort. Pediatrics (2010) 126(3):e644-50. doi:10.1542/peds.2010-0097

16. Shah PS, Ye XY, Synnes A, Rouvinez-Bouali N, Yee W, Lee SK, et al. Prediction of survival without morbidity for infants born at under 33 weeks gestational age: a user-friendly graphical tool. Arch Dis Child Fetal Neonatal Ed (2012) 97(2):F110-5. doi:10.1136/archdischild-2011-300143

17. Ge WJ, Mirea L, Yang J, Bassil KL, Lee SK, Shah PS, et al. Prediction of neonatal outcomes in extremely preterm neonates. Pediatrics (2013) 132(4):e876-85. doi:10.1542/peds.2013-0702

18. Fellman V, Hellström-Westas L, Norman M, Westgren M, Kallén K, Lagercrantz $\mathrm{H}$, et al. One-year survival of extremely preterm infants after active perinatal care in Sweden. JAMA (2009) 301(21):2225-33. doi:10.1001/jama.2009.771

19. Ancel PY, Goffinet F, Kuhn P, Langer B, Matis J, Hernandorena X, et al. Survival and morbidity of preterm children born at 22 through 34 weeks' gestation in France in 2011: results of the EPIPAGE-2 cohort study. JAMA Pediatr (2015) 169(3):230-8. doi:10.1001/jamapediatrics.2014.3351

20. Stoll BJ, Hansen NI, Bell EF, Walsh MC, Carlo WA, Shankaran S, et al. Trends in care practices, morbidity, and mortality of extremely preterm neonates, 1993-2012. JAMA (2015) 314(10):1039-51. doi:10.1001/jama.2015.10244

21. Gargus RA, Vohr BR, Tyson JE, High P, Higgins RD, Wrage LA, et al. Unimpaired outcomes for extremely low birth weight infants at 18 to 22 months. Pediatrics (2009) 124(1):112-21. doi:10.1542/peds.2008-2742 
22. Stichtenoth G, Demmert M, Bohnhorst B, Stein A, Ehlers S, Heitmann F, et al. Major contributors to hospital mortality in very-low-birth-weight infants: data of the birth year 2010 cohort of the German Neonatal Network. Klin Pädiatr (2012) 224(4):276-81. doi:10.1055/s-0032-1306344

23. Yeo KT, Lee QY, Quek WS, Wang YA, Bolisetty S, Lui K, et al. Trends in morbidity and mortality of extremely preterm multiple gestation newborns. Pediatrics (2015) 136(2):263-71. doi:10.1542/peds.2014-4075

24. Bührer C, Grimmer I, Metze B, Obladen M. The CRIB (Clinical Risk Index for Babies) score and neurodevelopmental impairment at one year corrected age in very low birth weight infants. Intensive Care Med (2000) 26(3):325-9. doi: $10.1007 /$ s001340051157

25. Rich WD, Auten KJ, Gantz MG, Hale EC, Hensman AM, Newman NS, et al. Antenatal consent in the SUPPORT trial: challenges, costs, and representative enrollment. Pediatrics (2010) 126(1):e215-21. doi:10.1542/peds.2009-3353

26. Moore T, Hennessy EM, Myles J, Johnson SJ, Draper ES, Costeloe KL, et al. Neurological and developmental outcome in extremely preterm children born in England in 1995 and 2006: the EPICure studies. BMJ (2012) 345:e7961. doi:10.1136/bmj.e7961

27. Faust K, Härtel C, Preuss M, Rabe H, Roll C, Emeis M, et al. Short-term outcome of very-low-birthweight infants with arterial hypotension in the first 24 h of life. Arch Dis Child Fetal Neonatal Ed (2015) 100(5):F388-92. doi:10.1136/ archdischild-2014-306483

28. Bassler D, Stoll BJ, Schmidt B, Asztalos EV, Roberts RS, Robertson CM, et al. Using a count of neonatal morbidities to predict poor outcome in extremely low birth weight infants: added role of neonatal infection. Pediatrics (2009) 123(1):313-8. doi:10.1542/peds.2008-0377

29. Martin CR, Dammann O, Allred EN, Patel S, O'Shea TM, Kuban KC, et al. Neurodevelopment of extremely preterm infants who had necrotizing enterocolitis with or without late bacteremia. J Pediatr (2010) 157(5):751-6. doi:10.1016/j.jpeds.2010.05.042

30. Farooqi A, Hagglof B, Sedin G, Serenius F. Impact at age 11 years of major neonatal morbidities in children born extremely preterm. Pediatrics (2011) 127(5):e1247-57. doi:10.1542/peds.2010-0806

31. Goldstein RF, Cotten CM, Shankaran S, Gantz MG, Poole WK, Eunice Kennedy Shriver National Institute of Child Health, et al. Influence of gestational age on death and neurodevelopmental outcome in premature infants with severe intracranial hemorrhage. J Perinatol (2013) 33(1):25-32. doi:10.1038/jp.2012.91

32. Parikh NA, Lasky RE, Kennedy KA, McDavid G, Tyson JE. Perinatal factors and regional brain volume abnormalities at term in a cohort of extremely low birth weight infants. PLoS One (2013) 8(5):e62804. doi:10.1371/journal. pone.0062804

33. Davis AS, Hintz SR, Goldstein RF, Ambalavanan N, Bann CM, Stoll BJ, et al. Outcomes of extremely preterm infants following severe intracranial hemorrhage. J Perinatol (2014) 34(3):203-8. doi:10.1038/jp.2013.162

34. Morriss FH Jr, Saha S, Bell EF, Colaizy TT, Stoll BJ, Hintz SR, et al. Surgery and neurodevelopmental outcome of very low-birth-weight infants. JAMA Pediatr (2014) 168(8):746-54. doi:10.1001/jamapediatrics.2014.307

35. Manley BJ, Roberts RS, Doyle LW, Schmidt B, Anderson PJ, Barrington KJ, et al. Social variables predict gains in cognitive scores across the preschool years in children with birth weights 500 to 1250 grams. J Pediatr (2015) 166(4):870-6. doi:10.1016/j.jpeds.2014.12.016

36. Hagmann CF, Halbherr M, Koller B, Wintermark P, Huisman T, Bucher $\mathrm{HU}$, et al. Interobserver variability in assessment of cranial ultrasound in very preterm infants. J Neuroradiol (2011) 38(5):291-7. doi:10.1016/j. neurad.2010.12.008

37. Hintz SR, Barnes PD, Bulas D, Slovis TL, Finer NN, Wrage LA, et al. Neuroimaging and neurodevelopmental outcome in extremely preterm infants. Pediatrics (2015) 135(1):e32-42. doi:10.1542/peds.2014-0898

38. Broitman E, Ambalavanan N, Higgins RD, Vohr BR, Das A, Bhaskar B, et al. Clinical data predict neurodevelopmental outcome better than head ultrasound in extremely low birth weight infants. J Pediatr (2007) 151(5):500-5. doi:10.1016/j.jpeds.2007.04.013

39. Stoll BJ, Hansen NI, Bell EF, Shankaran S, Laptook AR, Walsh MC, et al. Neonatal outcomes of extremely preterm infants from the NICHD Neonatal Research Network. Pediatrics (2010) 126(3):443-56. doi:10.1542/ peds.2009-2959

40. Hummler HD, Poets C. Mortality of extremely low birthweight infantslarge differences between quality assurance data and the national birth/ death registry. Z Geburtshilfe Neonatol (2011) 215(1):10-7. doi:10.105 5/s-0031-1271757

41. Malacova E, Kemp-Casey A, Bremner A, Hart R, Stewart LM, Preen DB. Live delivery outcome after tubal sterilization reversal: a population-based study. Fertil Steril (2015) 104(4):921-6. doi:10.1016/j.fertnstert.2015.06.042

42. Macdonald EM, Ng R, Bayoumi AM, Raboud J, Brophy J, Masinde KI, et al. Adverse neonatal outcomes among women living with HIV: a population-based study. J Obstet Gynaecol Can (2015) 37(4):302-9. doi:10.1016/ S1701-2163(15)30279-6

43. Patrick SW, Burke JF, Biel TJ, Auger KA, Goyal NK, Cooper WO. Risk of hospital readmission among infants with neonatal abstinence syndrome. Hosp Pediatr (2015) 5(10):513-9. doi:10.1542/hpeds.2015-0024

44. Macy ML, Zonfrillo MR, Cook LJ, Funai T, Goldstick J, Stanley RM, et al. Patient- and community-level sociodemographic characteristics associated with emergency department visits for childhood injury. J Pediatr (2015) 167(3):711-8. doi:10.1016/j.jpeds.2015.05.047

45. Cecil E, Bottle A, Cowling TE, Majeed A, Wolfe I, Saxena S. Primary care access, emergency department visits, and unplanned short hospitalizations in the UK. Pediatrics (2016) 137(2):1-9. doi:10.1542/peds.2015-1492

Conflict of Interest Statement: The authors declare that this work was done in the absence of any commercial or financial relationships that could be construed as a potential conflict of interest.

Copyright (c) 2016 Jeschke, Biermann, Günster, Böhler, Heller, Hummler and Bührer for the Routine Data-Based Quality Improvement Panel. This is an open-access article distributed under the terms of the Creative Commons Attribution License (CC BY). The use, distribution or reproduction in other forums is permitted, provided the original author(s) or licensor are credited and that the original publication in this journal is cited, in accordance with accepted academic practice. No use, distribution or reproduction is permitted which does not comply with these terms. 